\title{
Changes of Plasma Lipids and Erythrocyte Membrane Fluidity in Psoriatic Children
}

\author{
G. FERRETTI, O. SIMONETTI, A. M. OFFIDANI, L. MESSINI, B. CINTI, I. MARSHISEPPE, \\ G. BOSSI, AND G. CURATOLA \\ Clinica Dermatologica [O.S., A.M.O., L.M., G.B.], Istituto di Biochimica [G.F., G.C.], Laboratorio Analisi [B.C.], \\ Medicina del Lavoro [I.M.], Università degli Studi di Ancona, Ancona, Italy
}

\begin{abstract}
Psoriasis has been associated with an abnormal plasma lipid metabolism, and changes of erythrocyte membrane lipid composition and fluidity have been shown in adult patients. To investigate whether the alterations of plasma lipids appear also in pediatric patients, we have studied plasma lipids and lipoproteins in 15 prepubertal children affected by mild-to-moderate psoriasis with respect to healthy controls. The patients showed higher levels of plasma total cholesterol $(4.44 \pm 0.78$ versus 4.03 $\pm 0.58 \mathrm{mmol} / \mathrm{L}$ ), a significant increase of cholesterol associated with HDL $(1.39 \pm 0.26$ versus $1.13 \pm 0.28 \mathrm{mmol} /$ $\mathrm{L}, p=0.02$ ), and a significant decrease of the ratio LDL cholesterol to HDL cholesterol $(1.73 \pm 0.6$ versus $2.46 \pm$ $0.8, p=0.02$ ). By using fluorescence polarization of 1,6diphenyl-1,3,5-hexatriene, we have shown a significant increase in fluidity in erythrocyte membrane of psoriatic children that was associated with a slight, but not significant, decrease in the cholesterol to protein ratio $(422 \pm$ 127 versus $503 \pm 117 \mathrm{nmol} / \mathrm{mg}$ ). No significant changes of phospholipid fatty acid composition have been shown, in disagreement with previous studies in adult patients. Our results support the relation between childhood psoriasis and plasma lipid changes, which are likely related to the slight compositional changes in erythrocytes. However, the observed abnormalities are expressed differently in children than in adults. (Pediatr Res 33: 506-509, 1993)
\end{abstract}

\section{Abbreviations}

DPH, 1,6-diphenyl-1,3,5-hexatriene

HDL-C, cholesterol associated with high-density lipoprotein

LDL-C, cholesterol associated with low-density lipoprotein $\mathbf{P}_{\mathrm{f}}$, fluorescence polarization

TC, total cholesterol

TG, triglyceride

VLDL-C, cholesterol associated with very low-density lipoprotein

Psoriasis is a chronic inflammatory skin disease characterized by an accelerated turnover of epidermal cells and an incomplete differentiation in lesional epidermidis. The etiology of psoriasis is unknown, but genetic, metabolic, and immunologic mechanisms have been proposed (1). Various disorders of the plasma lipid and lipoprotein pattern that include an increase in $T G$ in VLDL and a decrease in HDL-C have been shown in adult

Received November 28, 1991; accepted November 5, 1992.

Correspondence: Dott. Gianna Ferretti, Istituto di Biochimica, Facoltà di Medicina e Chirurgia, Università degli Studi di Ancona, Via Ranieri, 60131 Ancona, Italia. patients with respect to controls (2). Valquist et al. (3) have also observed modifications of the fatty acid composition of plasma TG, phospholipids, and cholesterol esters in which lower content of linoleic and linolenic acids and higher levels of dihomo- $\gamma$ linolenic acid have been observed.

At the membrane level, modifications of phospholipid fatty acid composition with a significant increase in arachidonic acid have been shown in the plasma membrane of the skin cells in the psoriatic lesion (4). The abnormalities of fatty acid composition are not confined to epidermal cells but have been observed also in adipose tissue (3) and in erythrocytes in adult patients (5), suggesting that perturbation of lipid metabolism may be a generalized phenomenon in psoriasis. However, at present, it has not been established whether the lipid alterations are primary events or a consequence of an abnormal metabolism of the inflamed skin.

The studies on metabolic and functional alterations in psoriasis have been mostly limited to adult patients. Less attention has been paid to pediatric subjects, although psoriasis has an incidence of about $0.1 \%$ to $3 \%$ in childhood (6).

In this report, we have studied plasma lipids and lipoproteins in prepubertal patients with a duration of psoriasis ranging from 2 to $9 \mathrm{y}$. To investigate whether modifications of plasma lipoproteins may be associated with changes of erythrocyte membrane composition and fluidity, we studied fatty acid composition, cholesterol content, and fluidity in erythrocyte membrane of psoriatic children. In previous studies (7), we correlated changes in the lipid composition of circulating lipoproteins with abnormalities in erythrocyte membrane lipids and fluidity. We suggested that erythrocyte membrane could represent a sensitive model to reveal complex alterations of lipid metabolism, because mature red blood cells lack lipid biosynthetic pathways (8) and therefore depend on exchange processes with circulating lipoproteins for their membrane stability (9).

\section{MATERIALS AND METHODS}

Patients. We studied, with parental consent, 15 prepubertal patients (seven females and eight males, mean age $9.4 \pm 2.2 \mathrm{y}$ ) with psoriasis. In all patients, the disease was moderate and of nummular type, and less than $25 \%$ of the skin surface was involved at the time of examination. None of the patients had received any systemic or topical medication for at least $2 \mathrm{wk}$ preceding the study. The duration of disease ranged from 2 to 9 $y$. None of the patients had a history of cardiovascular disease or familial hyperlipidemia or known diabetes mellitus, and all had normal laboratory tests for liver and renal function.

The control group consisted of 16 healthy, nonobese children (six females and 10 males, mean age $9 \pm 2.3$ y) who periodically were checked at the Dermatological Institute of the University of Ancona. They were not taking any drugs and were known to have had normal plasma cholesterol and TG values on at least one previous occasion. Patients and controls came from the same 
region of Italy and had similar nutritional habits, which were evaluated by a questionnaire concerning their dietary habits.

The body mass index (i.e. weight in $\mathrm{kg}$ divided by the square of height in meters), taken as obesity index, was similar in both groups (mean value $17.65 \pm 2.8 \mathrm{~kg} / \mathrm{m}^{2}$ in controls and $17.73 \pm$ $2.2 \mathrm{~kg} / \mathrm{m}^{2}$ in psoriatic patients).

Preparation of erythrocyte membranes and study of membrane lipid composition. Five $\mathrm{mL}$ of blood were drawn from each subject, who had fasted for $12 \mathrm{~h}$ overnight. Blood was put into heparinized tubes and used for the preparation of erythrocyte membranes. Erythrocytes were washed three times with isotonic saline $(0.15 \mathrm{M} \mathrm{NaCl}, 10 \mathrm{mM}$ Tris $\mathrm{HCl}, \mathrm{pH} 7.4)$, and the buffy coat and plasma were removed each time. Erythrocyte membranes were prepared by hemolyzing the washed erythrocytes in $5 \mathrm{mM}$ phosphate buffer, $\mathrm{pH} \mathrm{8}$, according to the method of Steck and Kant (10). Membrane protein content was estimated by the method of Lowry et al. (11) using BSA as standard.

Lipids were extracted from erythrocyte membranes by chloroform $/$ methanol $(2: 1, \mathrm{vol} / \mathrm{vol})$ followed by chloroform/metha$\mathrm{nol} / \mathrm{H}_{2} \mathrm{O}(60: 30: 20, \mathrm{vol} / \mathrm{vol} / \mathrm{vol})(12)$. Cholesterol content was assayed enzymatically using cholesterol oxidase (13). The fatty acid methylesters were chromatographed by reverse-phase HPLC. All chromatographic equipment was from Kontron (Munich, Germany). The system comprised a model 420 pump, a 735 LC programmable UV detector, and a 1459 integrator. Solvent was acetonitrile/tetrahydrofuran/0.1\% $\quad \mathrm{H}_{3} \mathrm{PO}_{4}$ $50.4: 21.6: 28(\mathrm{vol} / \mathrm{vol} / \mathrm{vol})$, flowing at $1 \mathrm{~mL} / \mathrm{min}$. A 3- $\mu \mathrm{m}$ Supelcosil LC8 $15-\mathrm{cm} \times 4.6-\mathrm{mm}$ inside diameter column (Supelco, Bellefonte, PA) was the analytical column, and a stainless steel guard column $(2-\mathrm{cm} \times 4.6-\mathrm{mm}$ inside diameter $)$ packed with pellicular reversed-phase material was used. Detection of fatty acid methylesters was performed at $215 \mathrm{~nm}$ at an attenuation factor of 6 . Fatty acid methylesters were identified by chromatography with authentic standards and quantified using the chromatographic conditions previously described. The sum of all peak areas of the fatty acids identified was taken as $100 \%$.

Fluorescence polarization measurements. The hydrophobic fluorescent probe DPH (Aldrich Chemical Co., Germany) was used to investigate membrane fluidity in erythrocyte membranes. $\mathrm{DPH}$, from a $2 \times 10^{-3} \mathrm{M}$ stock solution in tetrahydrofuran, was added to one volume of erythrocyte membranes containing about $100 \mu \mathrm{g} / \mathrm{mL}$ of membrane protein to give a final DPH concentration of $10^{-6} \mathrm{M}(14)$.

Steady state fluorescence polarization measurements of DPH were performed using a Perkin-Elmer MPF66 spectrofluorimeter (Norwalk, CT) equipped with two glass prism polarizers. Excitation and emission wavelengths were 365 and $430 \mathrm{~nm}$, respectively. The steady state $P_{f}$ was obtained from the fluorescence intensities parallel $(\mathrm{I} \|)$ and perpendicular $(\mathrm{I} \perp)$ to the polarization direction of excitation light using the following equation: $P_{f}=$ $(\mathrm{I} \|-\mathrm{I} \perp \times \mathrm{g}) /(\mathrm{I} \|+\mathrm{I} \perp \times \mathrm{g})$ where $\mathrm{g}$ is an instrumental correction factor. Fluorescence values were also corrected for light scattering contributions by means of unlabeled membrane suspensions.

Analytical methods. TC and TG were routinely determined using enzymatic methods $(15,16)$ and diagnostic kits supplied from Boehringher (Mannheim, Germany) on a Synchron C5 analyzer (Beckman, Germany). An HDL fraction of plasma was obtained by the precipitation method (17) using Boehringer kits, and the levels of HDL-C were determined by the same method as in whole plasma.

LDL-C and VLDL-C were determined using the formula of Friedewald (18), in which VLDL-C can be calculated as plasma TG divided by 5 and LDL-C is calculated as total cholesterol (HDL-C + VLDL-C). It is assumed that, in fasted subjects a good correlation exists between values obtained by the method of Friedewald et al. (18) and those obtained according to the Lipid Research Clinic Program methodology (19). Amounts of apo B and apo Al were assayed by the electroimmunoassay procedure (20).

Statistics. All the results are expressed as mean \pm SD. Statistical differences between data from psoriatic patients and controls were determined according to the Mann-Whitney test using a computer program (Stat View II for Personal Computer Macintosh, Apple, Berkeley, CA).

\section{RESULTS}

Plasma lipids and apoproteins. The mean value of plasma TC was higher in psoriatic children than in controls, but the difference was not statistically significant (Table 1). Moreover, a significant increase in HDL-C $(p=0.02)$ and a significant decrease in the ratio of LDL-C to HDL-C $(p=0.02)$ were observed (Table 1). The aforementioned plasma lipid changes were not correlated with the duration of the disease (data not shown). No relevant modification of lipoprotein and apoprotein levels could be observed concerning psoriasis (Table 2).

In control subjects, the levels of apo B were positively correlated with plasma TC $(r=0.59, p<0.03)$; moreover, the levels of apo A1, the major peptide of HDL lipoproteins, were positively correlated with HDL-C $(r=0.89, p<0.002)$. In psoriatic children, similar to the results of controls, apo A1 was positively correlated with HDL-C $(r=0.88, p<0.001)$, and apo B correlated with TC $(r=0.91, p<0.001)$. However, abnormalities in the lipid-apolipoprotein relation are supported by the significant increase in the TC:apo B ratio $(p=0.003)$ and the significant decrease in the apo A1:HDL-C ratio $(p=0.003)$ in psoriatic children compared with the controls (Table 2).

Erythrocyte membranes. The mean value of $\mathrm{P}_{\mathrm{f}}$ of $\mathrm{DPH}$ in erythrocyte membranes of controls was $0.316 \pm 0.009$. The corresponding value in psoriatic children was slightly but significantly decreased $(0.304 \pm 0.007, p=0.01)$ (Table 3$)$ and indicates an increase in membrane fluidity in psoriatic subjects.

To investigate whether the changes of membrane fluidity are related to modifications of membrane lipids, we studied the phospholipid fatty acid composition and the cholesterol:protein ratio in erythrocyte membranes of psoriatic children and control children. The mean percentage values of the various fatty acids in erythrocyte membranes of controls were in agreement with the values reported by other authors in adult patients (21). No relevant changes of fatty acid composition have been shown in erythrocytes of psoriatic children; the level of linoleic acid (18:2) was lower $(20.5 \pm 1$ versus $21.35 \pm 1.37$, Table 4$)$, but the difference was not significant. Moreover, the cholesterol:protein ratio was lower in erythrocyte membranes of psoriatic patients $(422 \pm 127$ versus $503 \pm 117 \mathrm{nmol} / \mathrm{mg})$, but the difference was not significant (Table 3 ).

\section{DISCUSSION}

Psoriasis in middle-aged patients has been associated with alterations of lipid metabolism as evidenced by changes of plasmatic parameters with respect to control subjects (2). Elevated levels of TG in both VLDL and LDL, as well as a higher VLDL$\mathrm{C}$ have been reported in adult psoriatics; these abnormalities are more pronounced in patients with severe psoriasis (2). Contrasting results have been observed about serum $\mathrm{TC}$; it has been reported to be raised (22), normal (23), or lowered (24). No data are available so far in the literature about the plasma lipid and lipoprotein pattern in psoriatic children.

An increase in TC associated with a significant increase in HDL-C and a significant decrease in the LDL-C:HDL-C ratio have been shown in psoriatic children. The levels of apo Al and apo $B$ were not modified with respect to the controls, in agreement with Aguilar Martinez (25), in adult patients. Despite the absence of significant changes of the mean apoprotein values, there was a significant increase in the ratio of $\mathrm{TC}$ to apo $\mathrm{B}$ in patients, and the ratio of apo A1/HDL-C was significantly decreased with respect to the controls. All these results suggest modifications of plasma lipids and the plasma lipid-apolipoprotein relationships in psoriatic children.

At the membrane level, we have shown an increase in fluidity 
Table 1. Plasma lipids in psoriatic children and their matched healthy controls*

\begin{tabular}{|c|c|c|c|}
\hline & Controls & Patients & $p$ \\
\hline $\mathrm{TC}(\mathrm{mmol} / \mathrm{L})$ & $4.03 \pm 0.58(n=16)$ & $4.44 \pm 0.78(n=14)$ & NS \\
\hline $\mathrm{TG}(\mathrm{mmol} / \mathrm{L})$ & $0.80 \pm 0.22(n=16)$ & $0.88 \pm 0.56(n=10)$ & NS \\
\hline VLDL-C $(\mathrm{mmol} / \mathrm{L})$ & $0.36 \pm 0.10(n=16)$ & $0.38 \pm 0.12(n=10)$ & NS \\
\hline $\mathrm{LDL}-\mathrm{C}(\mathrm{mmol} / \mathrm{L})$ & $2.69 \pm 0.46(n=14)$ & $2.79 \pm 0.67(n=10)$ & NS \\
\hline $\mathrm{HDL}-\mathrm{C}(\mathrm{mmol} / \mathrm{L})$ & $1.13 \pm 0.28(n=14)$ & $1.39 \pm 0.26(n=14)$ & 0.02 \\
\hline LDL-C/HDL-C & $2.46 \pm 0.8 \quad(n=14)$ & $1.73 \pm 0.6 \quad(n=10)$ & 0.02 \\
\hline
\end{tabular}

* Values are mean $\pm \mathrm{SD}$.

Table 2. Plasma lipoproteins and apoproteins in psoriatic children and healthy controls*

\begin{tabular}{lccc}
\hline & $\begin{array}{c}\text { Controls } \\
(n=6)\end{array}$ & $\begin{array}{c}\text { Patients } \\
(n=15)\end{array}$ & $p$ \\
\hline$\alpha$-Lipoproteins (\%) & $30 \pm 4$ & $34 \pm 7$ & $\mathrm{NS}$ \\
$\beta$-Lipoproteins (\%) & $42 \pm 2$ & $48 \pm 6$ & $\mathrm{NS}$ \\
Pre- $\beta$-Lipoproteins (\%) & $21 \pm 5$ & $17 \pm 6$ & $\mathrm{NS}$ \\
Apo A1 (g/L) & $1.41 \pm 0.33$ & $1.47 \pm 0.16$ & $\mathrm{NS}$ \\
Apo B (g/L) & $0.87 \pm 0.13$ & $0.79 \pm 0.21$ & $\mathrm{NS}$ \\
Apo B/Apo A1 & $0.595 \pm 0.08$ & $0.548 \pm 0.197$ & $\mathrm{NS}$ \\
TC/apo B (mmol/g) & $4.36 \pm 0.47$ & $5.74 \pm 0.64$ & 0.003 \\
Apo A1/HDL-C (g/mmol) & $1.41 \pm 0.13$ & $1.05 \pm 0.13$ & 0.003 \\
\hline
\end{tabular}

$*$ Values are mean $\pm \mathrm{SD}$.

Table 3. $P_{f}$ value of DPH and cholesterol:protein ratio in erythrocyte membranes of controls and psoriatic patients

\begin{tabular}{lccc}
\hline & Controls & Patients & \\
& $(n=14)$ & $(n=15)$ & $p$ \\
\hline $\mathrm{P}_{\mathrm{f}}$ & $0.316 \pm 0.009$ & $0.304 \pm 0.007$ & 0.01 \\
$\begin{array}{l}\text { Cholesterol:protein ratio } \\
\text { (nmol/mg) }\end{array}$ & $503 \pm 117$ & $422 \pm 127$ & $\mathrm{NS}$ \\
\hline
\end{tabular}

Table 4. Erythrocyte membrane fatty acid composition in psoriatic children and controls

\begin{tabular}{lrr}
\hline \multicolumn{1}{c}{ Fatty acids } & \multicolumn{1}{c}{$\begin{array}{c}\text { Controls } \\
(n=14)\end{array}$} & \multicolumn{1}{c}{$\begin{array}{c}\text { Patients } \\
(n=15)\end{array}$} \\
\hline $16: 0$ & $30.98 \pm 1.06$ & $30.44 \pm 1.37$ \\
$16: 1$ & $1.51 \pm 0.45$ & $1.74 \pm 0.43$ \\
$18: 0$ & $14.11 \pm 2.01$ & $14.38 \pm 1.71$ \\
$18: 1$ & $17.78 \pm 1.33$ & $18.11 \pm 0.98$ \\
$18: 2$ & $21.35 \pm 1.37$ & $20.51 \pm 1.10$ \\
$20: 0$ & $0.32 \pm 0.19$ & $0.30 \pm 0.20$ \\
$20: 1$ & $0.31 \pm 0.20$ & $0.45 \pm 0.25$ \\
$20: 2$ & $1.34 \pm 0.32$ & $1.28 \pm 0.32$ \\
$20: 3$ & $2.04 \pm 0.46$ & $1.96 \pm 0.56$ \\
$20: 4$ & $6.90 \pm 1.32$ & $6.90 \pm 1.33$ \\
$22: 5$ & $1.18 \pm 0.48$ & $1.38 \pm 0.36$ \\
$22: 6$ & $2.11 \pm 0.87$ & $2.51 \pm 0.70$ \\
Polyunsaturated & $34.97 \pm 1.99$ & $34.56 \pm 2.36$ \\
Saturated & $45.42 \pm 2.18$ & $45.12 \pm 2.28$ \\
P/S* & $0.77 \pm 0.75$ & $0.76 \pm 0.83$ \\
\hline
\end{tabular}

${ }^{*} \mathrm{P} / \mathrm{S}$, polyunsaturated/saturated.

in erythrocytes of psoriatic children in absence of significant changes of phospholipid fatty acid composition; moreover, erythrocyte membrane showed a slight but not significant decrease in the cholesterol:protein ratio. Studies of Srinivsan et al. (26) have demonstrated that erythrocyte membrane cholesterol content is sensitive even to slight modifications of the level of plasma lipoproteins involved in plasma cholesterol transport. In various human diseases characterized by hormonal and/or metabolic alterations associated with modifications in the composition of circulating lipoproteins, concomitant changes in the lipids of the erythrocyte membrane have been shown (27). Mature erythrocyte does not contain lipoprotein receptors; moreover, the membrane cholesterol content depends on exchange, very active both in vitro and in vivo, of free cholesterol with plasma lipoproteins because the lipid biosynthetic pathways are absent $(8,9)$. LDL particles are the primary carriers of cholesterol from plasma to peripheral cells; in contrast, HDL play an important role in the reverse transport of cholesterol from tissue. The level of LDL in relation to HDL may influence the direction of lipid transfer between cells and plasma. The relative proportions of LDL-C and HDL-C (LDL-C:HDL-C ratio) particularly appear to be better related to membrane cholesterol content than their absolute levels as demonstrated by the positive correlation between LDL-C:HDL-C ratio and erythrocyte membrane cholesterol:protein ratio or cholesterol:phospholipid ratio (26). Therefore, we hypothesize that the lower values of the cholesterol:protein ratio in erythrocytes of psoriatic children could be related to the significant decrease of the LDL-C:HDL-C ratio in plasma.

The absence of significant changes of phospholipid fatty acid composition in erythrocytes of psoriatic children does not agree with previous results in adult patients (5). In fact, a significant increase in arachidonic acid and an increased susceptibility to lipid peroxidation have been shown in middle-aged psoriatic patients (5). These compositional changes have been related to the decrease of membrane fluidity in erythrocytes of adult patients (28). The absence of phospholipid fatty acid alterations suggests the existence of compensatory mechanisms maintaining phospholipid composition relatively constant in psoriatic children in spite of modifications of TC and HDL-C levels.

Psoriatic children included in our study showed a mild-tomoderate severity of the disease. Conversely, the relevant changes of phospholipid fatty acid composition in adult patients concerned subjects with a severe form of psoriasis involving more than $30 \%$ of skin (5). No data are available concerning erythrocyte membrane composition in patients with a mild-to-moderate form of psoriasis.

No significant correlation between biochemical findings and duration of the disease, ranging from 2 to $9 \mathrm{y}$, has been observed in the psoriatic children considered in our study. It is likely that the severity more than the duration of the disease could be of interest in metabolic alterations.

The absence of significant changes of fatty acids in psoriatic children does not justify a dietary treatment with fish oil as is prescribed for adult patients. Also of consideration is the fact that only a modest clinical improvement has been obtained in adult age (29). Furthermore, it has to be taken into account that the large increase of polyunsatured fatty acids in plasma lipoproteins and in biologic membranes increases the risk for lipid peroxidation (30).

In conclusion, our results support the relation between childhood psoriasis and plasma lipid modifications that are likely related to the slight compositional changes in erythrocytes. These abnormalities appear to be expressed differently in pediatric patients than in adult patients. The increase in TC suggests, for psoriatic children, an increased risk for atherosclerosis; however, it must be considered that the increase in TC is associated mainly with a significant increase in HDL-C, which is considered a protective factor. Inasmuch as it has been suggested that the protective effect of HDL resides mainly in the more floating fraction $\mathrm{HDL}_{2}(31)$, further studies are necessary to fully elucidate whether or not the risk for psoriatic children to develop athero- 
sclerosis in the future is increased and to establish whether the plasma lipid alterations are primary events or a consequence of an abnormal lipid metabolism of inflamed skin.

\section{REFERENCES}

1. Baker H 1986 Psoriasis. In: Rook A, Wilkinson DS, Ebling FJG, Champion RH, Burton JL (eds) Textbook of Dermatology, 4th Ed, Vol II. Blackwell Scientific Publication Ed., Oxford, UK, pp 1469-1478

2. Vahlquist C, Michaelsson G, Vessby B 1987 Serum lipoprotein in middle-aged men with psoriasis. Acta Derm Venereol 67:12-15

3. Vahlquist C, Berne B, Boberg M, Michaelsson G, Vessby B 1985 The fatty acid spectrum in plasma and adipose tissue in patients with psoriasis. Arch Dermatol Res 278:114-119

4. Hammerstrom S, Hamberg M, Samuelsson B, Duell EA, Stawski M, Voorhees JJ 1975 Increased concentration of non-esterified arachidonic acid, 12 Lhydroxy $5,8,10,14$ eicosatetraenoic acid, prostaglandin E2 and prostaglandin F $2 \alpha$ in epidermis of psoriasis: evidence for perturbed regulation of arachidonic acid levels in psoriasis. Proc Natl Acad Sci USA 72:5130-5134

5. Corrocher R, Ferrari S, De Gironcoli M, Bassi A, Olivieri O, Guarini S, Stanzial A, Barba AL, Gregolini L 1989 Effect of fish oil supplementation on erythrocyte lipid pattern, malondialdehyde production and glutathione activity in psoriasis. Clin Chim Acta 179:121-132

6. Jacobs AH, Farber EM, Nall L, Watson W 1989 Psoriasis. In: Ruiz Maldonado R, Parish LC, Beare JM (eds) Textbook of Pediatric Dermatology. Grune \& Stratton, Philadelphia, pp 203-217

7. Ferretti G, Curatola G, Bertoli E, Catassi C, Giorgi PL 1991 Erythrocyte membrane fluidity and changes of plasma lipid composition: a possible relationship in childhood obesity. Biochem Med Metabol Biol 46:1-9

8. Marks PA, Gellhorn A, Kidson C 1960 Lipid synthesis in human leukocytes, platelets and erythrocytes. J Biol Chem 235:2579-2583

9. Phillips MC, Johnson WI, Rothblat GH 1987 Mechanism and consequence of cellular cholesterol exchange and transfer. Biochim Biophys Acta 906:222276

10. Steck TL, Kant JA 1974 Preparation of impermeable ghosts and inside out vesicles from human erythrocyte membranes. In: Colowick SP, Kaplan NO (eds) Methods in Enzymology. Academic Press, London, pp 172-173

11. Lowry OH, Rosebrough NJ, Farr AL, Randall R 1951 Protein measurement with the Folin phenol reagent. J Biol Chem 193:265-275

12. Alling C, Gustavsson L, Kristenseeon AA, Wallertedt C 1984 Changes in fatty acid composition of major glycerophospholipids in erythrocyte membranes from chronic alcoholics during withdrawal. Scan J Clin Lab Invest 44:283 289

13. Ott P, Binggely Y, Brodbeck U 1982 A rapid and sensitive assay for determination of cholesterol in membrane lipid extracts. $685: 211-213$

14. Shinitzky M, Barenholz Y 1978 Fluidity parameters of lipid regions determined by fluorescence polarization. Biochim Biophys Acta 515:367-394
15. Allain CC, Poon LS, Chan CSG, Richmond W 1974 Enzymatic determination of total serum cholesterol. Clin Chem 20:470-474

16. Bucolo $G$, David $H, 1973$ Quantitative determination of triglycerides by the use of enzymes. Clin Chem 20:470-475

17. Finley PR, Schifman RB, Williams RI, Lichti DA 1978 Cholesterol in highdensity lipoprotein: use of $\mathrm{Mg}^{2+} /$ dextran sulfate in its enzymic measurement. Clin Chem 24:931-933

18. Friedewald WT, Levy RI, Fredrickson DS 1972 Estimation of the concentration of low-density lipoprotein cholesterol in plasma, without use of the preparative ultracentrifuge. Clin Chem 18:469-479

19. Cohn JS, McNamara JR, Schaefer EJ 1988 Lipoprotein cholesterol concentration in the plasma of human subjects as measured in the fed and fasted states. Clin Chem 34:2456-2459

20. Vessby B, Lithell H, Hellsing K, Ostund-Lindqvist AM, Gustaffson IB, Bober $J$, Ledermann H 1980 Effects of bezafibrate on the serum lipoprotein lipid and apolipoprotein composition, lipoprotein triglyceride removal capacity and the fatty acid composition of the plasma lipid esters. Atherosclerosis 37:257-269

21. Angelico F, Amodeo P, Borgogelli C, Cantafora A, Montali A, Ricci G 1980 Red blood cell fatty acid composition in a sample of Italian men on free diet. Nutr Metab 24:148-153

22. Tickner A, Mier PD 1960 Serum cholesterol, uric acid and proteins in psoriasis. Br J Dermatol 72:131-137

23. Benton JM, Brown PE, Church RE 1963 The serum cholesterol in psoriasis. Lancet 1:583-584

24. Peserico A, Zanatti G, Cipriani R, Veller-Fornasa C, Ziron L, Galassini F Pagnan A 1982 Studio dell'assetto lipidico in una casistica di soggetti psoriasici. Giorn It Dermetol Vener 117:15-17

25. Aguilar Martinez AA, Rodriguez PG, Antunez PA, Gil MCC, Gonzales FU, Perez AG 1989 Serum levels of apolipoproteins AI, AII and B in psoriasis. Dermatologica 179:200-201

26. Srinivsan SR, Amos C, Albares R, Bhandaru RR, Dalferes Jr ER, Webber LS, Berenson GS 1986 Influence of serum lipoproteins and carbohydrate metabolism on erythrocyte membrane composition in children: Bogalusa heart study. Metabolism 35:466-471

27. Owen JS, McIntyre N, Gillet M 1984 Lipoproteins, cell membranes and cellular functions. Trends Biochem Sci 5:238-242

28. Ferretti G, Offidani AM, Simonetti O, Valentino M, Curatola G, Bossi G 1989 Changes in membrane properties of erythrocytes and polymorphonuclear cells in psoriasis. Biochem Med Metab Biol 41:132-138

29. Maurice PDL, Allen BR, Barkley ASJ, Cockbill SR, Stammers J, Bather PC 1987 The effect of dietary supplementation with fish oil in patients with psoriasis. Br J Dermatol 1 17:599-606

30. Parthasarathy S, Khoo JC, Miller E, Barnett J, Witztom JL, Steinberg D 1990 Low-density lipoprotein rich in oleic acid is protected against oxidative modification: implications for dietary prevention of atherosclerosis. Proc Natl Acad Sci USA 87:3894-3898

31. Amolerson DW, Nichols AV, Pam SS, Lindgren FT 1978 High density lipoprotein distribution. Resolution and determination of three major components in a normal population sample. Atherosclerosis 29:161-179 